\title{
NOTAS SOBRE VARIANTES ORTOGRÁFICAS EN EL ESPAÑOL DE MÉXICO
}

Un hecho curioso e interesante en el trabajo lexicográfico es el de las variantes ortográficas de un vocablo. De un lado tenemos la grafía o las grafías canonizadas por la autoridad lingüística -en nuestro caso el $D R A E$, sustentada sobre una base etimológica-; de otro lado tenemos la fluctuación, la duda, el cambio. Nos encontramos siempre ante un problema de historia de la lengua: ¿cuándo una grafía deja de considerarse una falta? ¿cuando la mayoría de los hablantes cultos la usan, o cuando el DRAE la canoniza?

Al tratar de explicar una serie de variantes ortográficas, que aparecieron en el corpus del Diccionario del español de México (DEM), encontré que en la mayoría de los casos existía una lucha entre la ortografía etimológica, históricamente aceptada y conocida por un grupo de personas cultas, y una ortografía basada en la analogía o la etimología popular, generalmente muy difundida, aunque por lo regular no aceptada por los académicos. Así, por ejemplo, en el caso de ingerencia e injerencia ${ }^{1}$, en el $D R A E$ aparece INJERENCIA 'acción y efecto de injerirse (del lat. ínsérěre) entrometerse, introducirse en una dependencia o negocio'; INGERIR (del lat. ingérěre) aparece con el sentido único de 'introducir por la boca la comida o los medicamentos'. No se registra ingerencia como relacionado con gerencia y gerente y que vendrían del latín ingero 'llevar, ejercer, hacer en o dentro de'. En el corpus del $\mathrm{DEM}^{2}$ ingerencia apareció cinco veces ("A partir de entonces la ingerencia de esta potencia en la vida de los pueblos hispanoparlantes se volvió de lo más descarada") frente a una sola aparición de injerencia ("Posiblemente su injerencia en los problemas de sus vecinos del sur no ha sido lo suficientemente interesante"). Sin embargo, en el lenguaje periodístico de los últimos años, no incluido en nuestro corpus, aparece diariamente injerencia. La conclusión sería, en principio, que un diccionario del español de México debe registrar ambas grafías y que la definición aparecerá bajo la más frecuente. Aunque en el momento actual la prensa intente revitalizar la grafía con $j$ canonizada por la autoridad del DRAE, muchos hablantes cultos preferirán la grafía con $g$ debido no a un preciso conocimiento etimológico, sino a que existe un grupo de verbos terminados en -gerir (ingerir, digerir y sugerir) que son de uso frecuente.

1 A. Rosenblat. Buenas y malas palabras, p. 202.

${ }^{2}$ El corpus del Español de México contemporáneo consta de 1000 textos de 2000 palabras, fechados entre 1921 y 1973 , incluye lengua culta, subculta y subestandar. (El Diccionario del Español de México es un proyecto iniciado en el año de 1973 y que se realiza bajo la coordinación de L. F. Lara). 
frente a sólo un verbo terminado en -jerir (injerir o injerirse) de uso bastante restringido.

PRETENSIOSO y PRETENCIOSO ${ }^{3}$ son dos grafías de un vocablo, ninguna de las cuales ha sido registrada por el $D R A E$. La causa de esta ausencia podría explicarse por una memoria erudita que recuerda que se trata de un galicismo procedente de "pretentieux" y sería también esa memoria erudita, más liberal, la que al admitir el uso del vocablo justificaría una grafía con c. En su Diccionario Manual la Academia registra pretencioso como galicismo 'por presuntuoso o presumido'. Sin embargo, creo que el asunto puede tener un enfoque diferente: pretensioso está directamente emparentado con pretensión (del lat. praetensio, -onis) y de ahí que la grafía etimológicamente justificada sea con $s$.

Ahora bien, la fuerza de la ana logía ha tenido sus consecuencias: frente a sólo dos vocablos terminados en -sioso (ansioso y fantasioso) existe en amplísimo grupo de palabras terminadas en -cioso (silencioso, ambicioso, substancioso, jactancioso, licencioso, tendencioso, ocioso, capcioso, minucioso, bullicioso, cadencioso, gracioso, infeccioso, precioso, artificioso, malicioso, delicioso, pernicioso, supersticioso, juicioso, vicioso, etc.). De ahí que el hablante que escribe use con cierta frecuencia la grafía con $c$. En nuestro corpus esta grafía predominó: hubo siete apariciones con $c$ (por ejemplo, "Asevera que las intenciones pretenciosas de Marechal hacen menos humano el héroe principal"); frente a sólo dos con $s$ ("Precisamente ella era muy pretensiosa y no le alcanzaba lo que yo tenía"; "Yo daba pretensiosamente las órdenes en alemán").

Curiosamente, el problema de una doble grafía alcanza mínimamente a su pariente cercano, el vocablo pretensión, y esto a pesar de que el grupo de vocablos terminados en -sión (tensión, hipertensión, distensión, extensión) es mucho menor que el de aquellos terminados en -ción (atención, obtención, intención, abstención, manutención, contención, etc.).

En nuestro corpus aparece la grafía con $s$ cuarenta veces (como en "Imposible satisfacer las pretensiones de aumento de presupuesto"), frente a sólo tres ejemplos con $c$ ("Lo que más le importa es subrayar que sus pretenciones eran fundadas"; "Para que veas que una obra sin pretenciones dice mucho"). María Moliner en su Diccionario de uso del español registra la grafía pretencioso, tal vez justificando la escritura con $c$ como proveniente del francés "pretentieux". Al mismo tiempo que parece no establecer ningún lazo de parentesco con pretensión a la que registra con $s$ proveniente de un participio del verbo latino praetendere, praetensus. Corominas, $D C E C$, s.v. tender registra a base de $A$ ut., pretensión, y dice a renglón seguido: "pretencioso (que algunos escriben pretensioso), galicismo muy usual a pesar de las protestas de Baralt y sus sucesores". El Diccionario de autoridades registra pretender y sus derivados pretenso (a), pretensión y pretensor; pero no pretensioso, ni pretencioso. Como el sentido de pretensión 'aspiración impertinente o desmedida o afirmación de algo dudoso' se halla muy cercano del de pretencioso 'persona me se alaba o exagera sus méritos', esta cercanía de sentidos hace pensar en palabras emparentadas directamente, aunque, por lo visto, pretención tiene una historia independiente relacionada directamente con la palabra francesa. El uso mexicano parece coincidir con el registrado por María Moliner: pretensión y pretencioso.

\footnotetext{
${ }^{3}$ ROSENBLAT, op. cit., pp. 226-228.
} 
En EXUBER ANTE, EXHUBER ANTE, la fuerza de la analogía lleva a escribir con mucha frecuencia una $h$ intermedia no etimológica, pero que aparece en otros vocablos que principian con ex-, como: exhumación, exhumar, exhortación, exhortar, exhibición, exhibir, exhausto, etc.

A pesar de que la grafía con - $h$ es muy frecuente, me parece que aún se percibe, por lo general, como una falta ortográfica. Tal vez la introducción de esta $h$ se deba a que cuando ésta aparece después de la partícula ex parece dar énfasis y cierta independencia significativa a la partícula que le sigue; en las palabras en que $e x$ aparece seguida de una $h$ etimológica, generalmente se trata de un ex con el sentido de 'fuera de' al que se añadió otro radical que empezaba con $h$, como en ex thortari > exhortari > exhortar. En el caso de exhuberante y exuberancia, la palabra latina parece haberse formado de una partícula $e x$ a la que se agregó el radical $u b e r$ 'fértil', sin la $h$ que en ocasiones se añade por analogía con palabras que sí la llevan. Corominas. s.v. ubre, las registra desde el siglo xvi, sin extenderse en explicaciones. En nuestro corpus, no apareció ningún ejemplo, y, sin embargo, sí hubo tres ocurrencias de exuberante y cuatro de exuberancia con la ortografía etimológica ("Locos muy inteligentes, con una vitalidad exuberante y excepcionalmente encauzada al placer de la disciplina y la creación"; "Los mascarones con plumas, la exuberancia en la ornamentación y las flores de grandes pétalos").

GIRA y JIRA ${ }^{4}$ ha sido ampliamente tratado por Rosenblat; baste decir ahora, que ya el $D R A E$ registra GIRA como un derivado del verbo girar y con dos acepciones: l) 'Excursión o viaje de una o varias personas por distintos lugares, volviendo al punto de partida' y 2) 'Serie de actuaciones sucesivas de una compañía teatral o de un artista en diferentes localidades'.

Sea o no verdad que gira es un derivado de girar, lo cierto es que el hablante hace relación entre ambas palabras; cosa que no sucede, ni sucedía, con la grafía supuestamente etimológica de jira, largamente defendida por eruditos de la talla de Cuervo y Corominas. Éste señala que la palabra con legitimidad etimológica es jira 'banquete opíparo' tomado del francés antiguo chiere 'comida de calidad'. Dice que la Academia, en 1843 , la define ya como 'banquete campestre que se hace entre amigos', tal vez influida por la falsa relación con girar evocando la idea de una excursión o ida al campo. Corominas añade que "posteriormente la alteración se hizo más grave entre ciertos escritores semicultos, que dieron en desenterrar este vocablo del léxico, y arbitrariamente lo hicieron sinónimo de 'excursión, viaje a través de una comarca' " y cita a Cuervo para quien "sin duda la frase «dar una vuelta» les ha sugerido la empecatada idea de que aquella palabra sale de girar; por eso ponen la g". Concluye Corominas que lo más grave de todo esto es que "la Academia, después de resistir mucho tiempo ante ese error, ha acabado por darle consagración en sus últimas ediciones, admitiendo artificialmente junto al tradicional jira, una gira, paseo, excursión recreativa emprendida por una reunión de personas".

En nuestro corpus hubo treinta ocurrencias de gira ("El presidente inició su gira de trabajo de dos días por el Estado de México", "El actor y empresario Muravama empezará a preparar una gira teatral por sudamérica"); frente a sólo dos de jira ("Tantas fueron las jiras artísticas de Mozart, que resultaría tedioso enumerarlas"). Es evidente que la grafía preferida y

\footnotetext{
+ ROSENBIAT. op. cit., pp. $126-130$.
} 
generalmente utilizada es gira, sin embargo, aún perdura la grafía jira como una variante ortográfica culta y de poco uso.

El DRAE registra las variantes TRASTROCAR y TRASTOCAR aunque con sentidos levemente diferentes (trastocar 'trastornar, revolver'.'Trastornarse, perturbarse la razón'. Trastrocar 'mudar el ser o estado de una cosa, dándole otro diferente del que tenía'), y hace hincapié en que la más usada es trastrocar. En México, en cambio, trastrocar es una forma que está desapareciendo y se prefiere trastocar, quizá por disimilación. Pero en nuestro corpus el único ejemplo registrado es de trastrocar ("Cuando todo se trastrueca en España, con el descubrimiento de América y la sed de oro"), debido seguramente a que la persona que escribe, cuando tiene duda, recurre al diccionario y utiliza la forma que considera correcta, aunque ésta no coincida con la forma usada coloquialmente.

El diccionario de la Academia registra sólo ILAción (del latín illatio, -ōnis). 'Acción y efecto de inferir una cosa de otra. Trabazón razonada de las partes de un discurso'. HiLACIÓn no aparece, aunque el hablante la asocia normalmente con 'el hilo de las ideas', 'el hilo del discurso' y con el verbo hilar (del lat. filare); desgraciadamente Corominas no registra ni hilar, ni ilar, ni los sustantivos correspondientes para poder argumentar. Una ratificación de ello es la tercera acepción figurada del verbo hilar en el $D R A E$ : 'discurrir, trazar o inferir unas cosas de otras'. En nuestro corpus no aparecieron los vocablos ilación, ni hilación, pero en una ocurrencia del verbo hilar podemos leer: "hilar una serie de palabras que surgen unas de otras de sus rasgos fonéticos". Se puede suponer que en general se ignora, por su poco uso, el vocablo ilación, mientras que hilo e hilar son dos vocablos de uso frecuente y que además poseen los sentidos que cubre ilación.

En el caso de PUYa y PULLA el $D R A E$ registra la última con la acepción de 'dicho con que indirecta o embozadamente se zahiere o reconviene a una persona', y puya como 'punta acerada que en una extremidad tienen las varas o garrochas de los picadores y vaqueros, con la cual estimulan o castigan a las reses'. En México, sin embargo, existe entre personas cultas una notable preferencia por la grafía puya en la expresión 'echar pullas' que a veces parece deberse al conocimiento y asociación con la puya de los picadores y vaqueros. Podría explicarse también por el grupo de vocablos terminados en -uya (tuya, suya, cuya, aleluya, huya, incluya, concluya, influya, etc.), mucho mayor que aquél de los terminados en -ulla (hulla, patrulla, casulla, magulla y grulla). Aquí, al parecer, la etimología popular ha ganado la partida a la etimología culta.

En México parece ser muy frecuente DESTORNILLARSE de risa, pues se asocia con tornillo; mientras que la grafía etimológica DESTERNILLARSE (relacionada con las ternillas, cartílagos) al no ser transparente para el hablante que escribe, es poco usada. Sin embargo, en nuestro corpus hubo tan sólo una ocurrencia de este vocablo y con esta grafía ("Con sarcasmo ladino se desternillaba para hacerse oír hasta afuera si era posible"). Se puede decir que aunque el de uso común es destornillarse, la persona que quiere escribir y tiene duda recurre al diccionario y registra la grafía que allí encuentra, aunque no coincida con su uso como hablante.

Semejante al anterior, es el caso de ARRELLANARSE ARRELLENARSE. Frecuentemente se prefiere arrellenarse por su relación con relleno vocablo frecuente, frente a rellano sólo usado en un reducido número de textos 
literarios. Sin embargo, la grafía registrada en nuestro corpus fue arrellanarse ("Se da vuelta hacia la pared, de espaldas a Piedad y se arrellana para dormir"). De nuevo porque el que escribe trata de hacerlo de acuerdo con una norma de corrección escrita y registrada en el diccionario.

HOJEAR Y OJEAR (HOJEADA Y OJEADA) son sinónimos en cierto sentido, pues ambos se relacionan o refieren al mismo tipo de objetos: libros, cuadernos, etc. EL DRAE registra hojear con el sentido de 'mover o pasar ligeramente las hojas de un libro o cuaderno (en ocasiones) leyendo de prisa algunos pasajes para tomar de él un ligero conocimiento' y ojear como 'dirigir los ojos y mirar con atención a determinada parte'. EL DRAE registra únicamente el sustantivo ojeada 'mirada pronta y ligera' pero no hojeada.

En nuestro corpus apareció solamente el verbo hojear, con ocho ocurrencias ("Daniel parece hojear un mugroso cuaderno de fotografías de familia"); el sustantivo hojeada se registró tres veces ("¿Por qué no le das una hojead a a estos libros que le traje a Cristián?" y ojeada tuvo dos ocurrencias ("Aun los más escépticos no pueden dejar de dar una rápida ojeada al horóscopo de diarios y revistas").

Podríamos concluir que existe una preferencia por hojear y hojeada asociada seguramente con las hojas de libros, cuadernos, etc., mientras que ojear y ojeada relacionada con ojo se usan con poca frecuencia y tal vez tienden a desaparecer. Hojear se usa en infinitivo y en sus formas conjugadas (hojearnos, hojeabas). Hojeada se usa frecuentemente en la perífrasis echar una hojeada. Ojear sólo parece usarse en infinitivo y en lugar de las formas conjugadas se prefiere la perífrasis echar una ojeada cuando se trata de objetos que no están constituidos por hojas, pero que pueden ser vistos u observados: "Échale una ojeada al coche", "Echale una ojeada al niño".

ACECHAR y ASECHAR ${ }^{5}$ es problema histórico resuel to por el uso en beneficio de acechar, pero aún registrada con ambas grafías, en el $D R A E$. En él se pretende darlas como dos palabras con acepciones diferentes: en nuestro corpus, por el contrario, se registró con ambas grafías y un solo sentido: 'observar, aguardar cautelosamente con algún propósito'.

Tenemos más información sobre AVALANZARSE y ABALANZARSE sobre todo a través del artículo de $\mathrm{A}$. Pariente ${ }^{6}$. En el $D R A E$ aparecen registradas abalanzar y abalanzarse con el sentido de 'pesar en la balanza. Igualar los pesos, compensar, contrapesar'; en el español actual de México, esta primera acepción parece desconocida y sin uso. La acepción del verbo pronominal 'lanzarse con ímpetu, con fuerza, hacia o sobre algo' es en México la más conocida y frecuente; en nuestro corpus, sin embargo, no apareció tal sentido con esta grafía, sino con la grafía avalanzarse.

Tres concordancias pertenecientes a distintos textos literarios se registraron: una provenía de un cuento publicado por la Revista de la UNAM, otra de un cuento aparecido en la Revista de Bellas Artes y la última en $M$ is libros de Nellie Campobello: (1 "El juez le señaló el teléfono, la viuda se avalanzó sobre el aparato y trató de lograr comunicación"; 2 "Creyéndose dueño del terreno y de la acción, por la superioridad numérica, se avalanza sobre la caballería villista, sin imaginar la emboscada que les estaban

5 YAKOV MALKIEL, "Old Spanish assechar and its variants", $H R, 17$ (1949), 183-232.

"Á NGel Pariente, “¿Abalanzarse o avalanzarse?”, RFE, 51 (1968), 229-238. 
tendiendo"; 3 "Mezquinos, de palabras burdas, de cabelleras gorgónicas, que se te avalanzan y te arrastran y te llevan y me insultan").

Ante este hecho, llevé a cabo una encuesta entre personas cultas; la mayoría aseguró escribirla con $v$ (avalanzarse) y relacionarla automáticamente con avalancha, por lo que se puede ver estamos ante un caso de etimología popular.

En su artículo dice Pariente que la indecisión entre dos grafías (abalanzarse y avalanzarse) abarca varios siglos y que incluso el Diccionario de Autoridades (1726) "no se atrevió a adoptar una posición, pues se limita a exponer las diversas etimologías propuestas, y a observar con cautela que los más de los diccionarios y autores prefieren la escritura con $b$; pero que desde Cuervo (Diccionario de construcción y régimen, 1886-1893), y de acuerdo con su hipótesis, "se ha admitido por todos que abalanzar "equilibrar, pesar, poner la balanza en el fiel' y ab/valanzarse 'arrojarse con ímpetu' son más que formas de un verbo único abalanzar, derivado de balanza lat. vulg. bilancia". Esto "ha hecho creer que la escritura con $b$ es la única escritura correcta de la palabra, supuesta única en sus diversas acepciones" y "que se ha impuesto como norma de la escritura culta... inatacable sobre el supuesto de la etimología universalmente aceptada".

Pariente da como posible etimología de avalanzarse un avant-lanzarse 'lanzarse hacia adelante' independiente del abalanzar balanza 'equilibrar' y cuya grafía con $v$ estaría relacionada con la de otros derivados compuestos de avant como avanzar, avante, vanguardia, etc., por tanto concluye que "el que se introdujese una b en avalanzarse fue el resultado de una etimología popular que luego ofuscó a los gramáticos" y propone "restaurar la escritura de avalanzarse".

Interesante es que sea el escritor quien en un momento dado alteró la ortografía etimológica por el deseo de encontrar una motivación a un signo que para él era opaco y parecía no poderse relacionar sino con balanza, y que sea ahora, también, el hablante quien, al no poder relacionar el significado que conoce y usa de abalanzar con balanza, le devuelva su ortografía etimológica, avalanzarse, al relacionarlo con avalancha que, actualmente, tiene el sentido de 'algo que se precipita con ímpetu y en gran cantidad', bastante más cercano del 'lanzarse con ímpetu y precipitación'.

Todos estos casos me llevan a pensar sobre el problema de corrección para la lexicografía y, concretamente, para un diccionario de lengua. ¿Cuál es el momento en que una falta de ortografía se convierte en una variante ortográfica? ¿En qué momento puede tomarse la decisión de sancionar como correcta una falta de ortografía? ¿Cuando ha demostrado el filólogo su legitimidad etimológica, o cuando la estadística nos muestra que una mayoría de personas cultas usa tal grafía?

Podemos concluir que a pesar de que la ortografía se apoya en reglas por lo general rígidas y constantes, existen, sin embargo, cambios en las condiciones para la sanción de corrección que tienen que ver con circunstancias históricas. Cuando el cambio es un hecho consumado deja de ser tema de discusión; cuando el cambio está en proceso es objeto de polémica; los lectores y la historia tienen la última palabra. 